Publisher: Research Council of Science and Technology, Biratnagar, Nepal p. 128

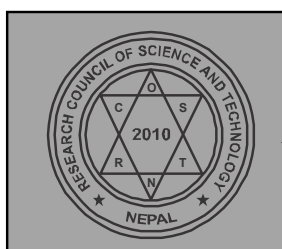

BIBECHANA

A Multidisciplinary Journal of Science, Technology and Mathematics

ISSN 2091-0762 (online)

Journal homepage: http://nepjol.info/index.php/BIBECHANA

\title{
Conductometric study of nickel chloride in ethanol-water mixed solvent media at various temperatures
}

\author{
Nabin Basnet ${ }^{1}$, Ajaya Bhattarai ${ }^{2 *}$ \\ ${ }^{1}$ Department of Chemistry, Damak Multiple Campus, Tribhuvan University, Damak, Nepal \\ ${ }^{2}$ Department of Chemistry, M.M.A.M.C., Tribhuvan University, Biratnagar, Nepal \\ E-mail: bkajaya@yahoo.com \\ Accepted for publication: December 20, 2014
}

\begin{abstract}
The conductivity measurement of nickel chloride has been done in binary solvent of the ethanol-water system. The different percentage of ethanol including 10, 20, 30, 40, 50, 60, 70, 80, 90 and $100(\mathrm{v} / \mathrm{v})$ has been chosen as binary solvents. The concentration of the electrolyte in the prepared solutions varies from 0.008 to $0.1 \mathrm{~mol}^{-1} \mathrm{l}^{-1}$ for temperatures $298.15 \mathrm{~K}, 303.15 \mathrm{~K}$ and $308.15 \mathrm{~K}$. The conductivity of the electrolyte decreases with increase in ethanol content in the solvent at a particular temperature, which is due to the decrease in dielectric constant of the medium. The conductivity increases with increase in temperature and concentration, due to increase in mobility of ions and number of ions from observed electrolyte respectively.
\end{abstract}

DOI: http://dx.doi.org/10.3126/bibechana.v12i0.11789

(C) 2014 RCOST: All rights reserved.

Keywords: Binary solvent; Nickel Chloride; Ethanol-water mixed solvent media; Conductivity.

\section{Introduction}

An electrolyte is the substance which can conduct electric current in aqueous solution, non-aqueous solution or in molten state. In electrolytes, freely movable ions are the charge carriers, so that these substances are electrically conductive. The electrical conductivity provides useful information in the area of engineering and in corrosions area provides useful information for assessing the corrosively of aqueous media and for the design of cathodic protection system. Also, it is used to gain insight into the properties of electrolyte solutions and evaluate characteristic quantities such as dissociation constants [1]. The conductance measurements provide valuable information regarding the ion-ion, ion-solvent interaction and solvent structure for both aqueous and binary solvent systems. The conductance in different electrolytes in aqueous solution have been extensively reported in literature, but in mixed solvent media including ethanol-water binary solvent is rare[2], also the conductivity measurement of transition metal salts is very rarely found in literature, so we have been selected $\mathrm{NiCl}_{2}$ for our study. Moreover, it is interesting that the $\mathrm{NiCl}_{2} 6 \mathrm{H}_{2} \mathrm{O}$ is moderately soluble even in the absolute ethanol. In recent, several studies have reported that the nature of the spherical ions, having a large variation in size in aqueous mixtures of the alcohols, has received considerable attention [3]. It was reported in the previous work [4] that potassium halides are structured breakers in ethanol-water 
Basnet and Bhattarai/ BIBECHANA 12 (2015) 128-134: p.129

mixtures and the maximum in breaking power occurs at 0.1 mole fraction of ethanol. The conductance of Sodium nitrate in ethanol - water mixtures were measured at $308.15 \mathrm{~K}$ in 1979 [5].

The measurement of conductance of sodium chloride, potassium bromide, sodium bromide, potassium chloride, and also potassium nitrate in pure water and ethanol-water mixed solvent media has been done $[6,7,8,9,10]$. This paper deals with the conductance behavior of nickel chloride in ethanolwater mixed solvents covering a range of dielectric constant values at temperature 298.15, 303.15 and $308.15 \mathrm{~K}$.

\section{Experimental}

The Ethanol is purchased from Merck, India which was then distilled with phosphorous pentoxide and again redistilled over calcium hydride. The purified ethanol had a density of $0.78097 \mathrm{gcm}^{-3}$ at 303.15 $\mathrm{K}$. The density of ethanol was measured by the use of an Ostwald-Sprengel type pycnometer of about $25 \mathrm{~cm}^{3}$ capacity. The pycnometer was then tightly fixed in a thermostat at the experimental temperatures within $0.005 \mathrm{~K}$ for at least 15 minutes to have thermal equilibrium with thermostat. After thermal equilibrium was attained, the mass of the pycnometer was measured with an electronic balance having $0.0001 \mathrm{gm}$ sensitivity, made by KERN company, Germany and the density was calculated. The water used in preparation of binary solvent was obtained by triply distillation of ordinary water using potassium permanganate and sodium hydroxide. The purified water has a specific conductance less than $10^{-6}{\mathrm{~S} . \mathrm{cm}^{-1}}^{\text {at }} 303.15 \mathrm{~K}$. The dielectric constant of the binary solvent of ethanol-water mixtures at the experimental temperatures were obtained by regressing the relative permittivity data as a function of solvent composition from the literature [3].

The $\mathrm{NiCl}_{2} \cdot 6 \mathrm{H}_{2} \mathrm{O}$ employed in these investigations was purchased from SD Fine Chem Limited, Mumbai, India. Conductance measurements were carried out on a Pye-Unicam PW 9509 conductivity meter at a frequency of $2000 \mathrm{~Hz}$ using a dip-type cell with a cell constant of $1.15 \mathrm{~cm}^{-1}$ and having an uncertainty of $0.01 \%$. The cell was calibrated by the method of Lind and co-workers[11 ], 1959 using the aqueous potassium chloride solution. The measurements were made in a water bath maintained within $\pm 0.005 \mathrm{~K}$ of the desired temperature. The details of the experimental procedure have been described earlier $[12,13]$. To ensure the reproducibility of the results, several independent solutions were prepared and runs were performed. Due correction was made for the specific conductance of the solvent by subtracting the specific conductance of the relevant solvent medium from those of the electrolyte solutions.

In order to avoid moisture pickup, all solutions were prepared in a dehumidified room with utmost care. In all cases, the experiments were performed three times.

\section{Results and Discussion}

The water and alcohol have different structures; the structure of alcohol is much simpler than that of water. The water and alcohol molecules associate much less strongly, and form polymeric H-bonded chains, rather than large cluster, which rarely contain 5 to 7 molecules for sterically hindered alcohols [14]. The hydrogen bonding network strengthening and tetrahedral like water network changes to zigzag chain structure of the system with increase in alcohol concentration in the ethanol-water system [15]. The hydrogen bonding and a closer packing of the molecules by the attraction allows a larger number of molecules of the hydrated ethanol to fit into the same space, thus decreasing the overall volume. The density of the binary solvent decreased with the increase of ethanol content for the 
ethanol-water mixed solvent system $[10,16,17]$. In ethanol-water mixtures, solvent-solvent interactions play a considerable part and properties of these mixtures cannot always be interpreted on the basis of the continuous miscibility of the components in all mixtures. These mixtures possess also pronounced structures which vary with temperature and ethanol content. The relative permittivity of the medium (fig. 1) decreased at a given temperature with increasing in the ethanol content $[3,6,7,8$, $10]$ in the binary solvent system. The specific conductance data taken during the study were given below in the Tables 1-3, in the electrolyte concentration ranges from 0.008 mol. $1^{-1}$ to $0.1 \mathrm{~mol}^{-1}{ }^{-1}$.

Table 1: Concentration and Sp. conductance $(\kappa, \mathrm{mS} / \mathrm{cm})$ of $\mathrm{NiCl}_{2}$ in various $\%(\mathrm{v} / \mathrm{v})$ of Ethanol at $298.15 \mathrm{~K}$

\begin{tabular}{|c|c|c|c|c|c|c|c|c|c|c|c|}
\hline \multirow{2}{*}{ S.N. } & Conc. & \multicolumn{9}{|c|}{ Specific conductance of $\mathbf{~ N i C l}_{\mathbf{~}}$ in various \% } \\
\cline { 3 - 12 } & $(\mathrm{Mol} / \mathrm{L})$ & $\mathbf{1 0}$ & $\mathbf{2 0}$ & $\mathbf{3 0}$ & $\mathbf{4 0}$ & $\mathbf{5 0}$ & $\mathbf{6 0}$ & $\mathbf{7 0}$ & $\mathbf{8 0}$ & $\mathbf{9 0}$ & $\mathbf{1 0 0}$ \\
\hline 1 & 0.100 & 12.89 & 10.13 & 8.14 & 6.70 & 5.66 & 4.75 & 3.99 & 3.15 & 2.27 & 1.07 \\
\hline 2 & 0.080 & 10.85 & 8.54 & 6.82 & 5.62 & 4.62 & 3.95 & 3.35 & 2.67 & 1.95 & 0.91 \\
\hline 3 & 0.060 & 8.30 & 6.54 & 5.26 & 4.31 & 3.35 & 3.07 & 2.59 & 2.07 & 1.52 & 0.71 \\
\hline 4 & 0.040 & 5.70 & 4.43 & 3.59 & 2.95 & 2.47 & 2.07 & 1.79 & 1.43 & 1.03 & 0.51 \\
\hline 5 & 0.020 & 3.07 & 2.39 & 1.99 & 1.63 & 1.39 & 1.15 & 0.99 & 0.83 & 0.68 & 0.31 \\
\hline 6 & 0.010 & 1.87 & 1.47 & 1.27 & 1.07 & 0.91 & 0.83 & 0.75 & 0.63 & 0.47 & 0.23 \\
\hline 7 & 0.008 & 1.51 & 1.23 & 1.15 & 1.03 & 0.83 & 0.71 & 0.63 & 0.55 & 0.35 & 0.19 \\
\hline
\end{tabular}

Table 2: Concentration and $\mathrm{Sp}$. conductance $(\kappa, \mathrm{mS} / \mathrm{cm})$ of $\mathrm{NiCl}_{2}$ in various $\%(\mathrm{v} / \mathrm{v})$ of Ethanol at $303.15 \mathrm{~K}$

\begin{tabular}{|c|c|c|c|c|c|c|c|c|c|c|c|}
\hline \multirow{2}{*}{ S.N. } & Conc. & \multicolumn{9}{|c|}{ Specific conductance of $\mathbf{~ N i C l}_{\mathbf{2}}$ in various \% } \\
$(\mathbf{M o l} / \mathrm{L})$ & $\mathbf{1 0}$ & $\mathbf{2 0}$ & $\mathbf{3 0}$ & $\mathbf{4 0}$ & $\mathbf{5 0}$ & $\mathbf{6 0}$ & $\mathbf{7 0}$ & $\mathbf{8 0}$ & $\mathbf{9 0}$ & $\mathbf{1 0 0}$ \\
\hline 1 & 0.100 & 14.65 & 11.73 & 9.50 & 7.82 & 6.50 & 5.54 & 4.35 & 3.59 & 2.55 & 1.21 \\
\hline 2 & 0.080 & 12.45 & 9.90 & 7.98 & 6.54 & 5.54 & 4.60 & 3.79 & 3.03 & 2.15 & 0.95 \\
\hline 3 & 0.060 & 9.58 & 7.62 & 6.14 & 5.02 & 4.23 & 3.59 & 2.91 & 2.39 & 1.71 & 0.79 \\
\hline 4 & 0.040 & 6.54 & 5.22 & 4.27 & 3.51 & 2.87 & 2.47 & 2.03 & 1.63 & 1.23 & 0.55 \\
\hline 5 & 0.020 & 3.55 & 2.95 & 2.35 & 1.91 & 1.51 & 1.35 & 1.19 & 0.99 & 0.75 & 0.35 \\
\hline 6 & 0.010 & 1.91 & 1.71 & 1.43 & 1.15 & 0.95 & 0.83 & 0.75 & 0.67 & 0.55 & 0.31 \\
\hline 7 & 0.008 & 1.63 & 1.51 & 1.27 & 1.03 & 0.87 & 0.75 & 0.67 & 0.55 & 0.43 & 0.27 \\
\hline
\end{tabular}

Table 3: Concentration and $\mathrm{Sp}$. conductance $(\kappa, \mathrm{mS} / \mathrm{cm})$ of $\mathrm{NiCl}_{2}$ in various $\%(\mathrm{v} / \mathrm{v})$ of Ethanol at $308.15 \mathrm{~K}$

\begin{tabular}{|c|c|c|c|c|c|c|c|c|c|c|c|}
\hline \multirow{2}{*}{ S.N. } & Conc. & \multicolumn{9}{|c|}{ Specific conductance of $\mathbf{~ N i C l}_{\mathbf{2}}$ in various \% $(\mathbf{v} / \mathbf{v})$ of Ethanol at $\mathbf{3 0 8 . 1 5} \mathbf{~ K}$} \\
\cline { 3 - 13 } & $(\mathbf{M o l} / \mathrm{L})$ & $\mathbf{1 0}$ & $\mathbf{2 0}$ & $\mathbf{3 0}$ & $\mathbf{4 0}$ & $\mathbf{5 0}$ & $\mathbf{6 0}$ & $\mathbf{7 0}$ & $\mathbf{8 0}$ & $\mathbf{9 0}$ & $\mathbf{1 0 0}$ \\
\hline 1 & 0.100 & 17.20 & 13.73 & 10.89 & 9.14 & 7.66 & 6.18 & 5.14 & 3.91 & 2.71 & 1.23 \\
\hline 2 & 0.080 & 14.49 & 11.57 & 9.14 & 7.62 & 6.42 & 5.14 & 4.35 & 3.31 & 2.31 & 1.03 \\
\hline 3 & 0.060 & 11.25 & 8.98 & 7.06 & 5.9 & 4.95 & 4.07 & 3.39 & 2.67 & 1.83 & 0.83 \\
\hline 4 & 0.040 & 7.94 & 6.30 & 5.02 & 4.11 & 3.35 & 2.87 & 2.39 & 1.91 & 1.31 & 0.59 \\
\hline 5 & 0.020 & 4.35 & 3.47 & 2.79 & 2.31 & 1.91 & 1.63 & 1.35 & 1.07 & 0.75 & 0.35 \\
\hline 6 & 0.010 & 2.59 & 2.03 & 1.63 & 1.27 & 1.15 & 1.03 & 0.87 & 0.75 & 0.51 & 0.23 \\
\hline 7 & 0.008 & 2.27 & 1.71 & 1.43 & 1.19 & 0.95 & 0.83 & 0.78 & 0.59 & 0.47 & 0.19 \\
\hline
\end{tabular}


Table 4: Experimental slopes, correlation coefficients of fits $\left(a \mathrm{r}^{2}\right)$ of Nickel Chloride and dielectric constant of Ethanol-Water mixtures at different temperatures

\begin{tabular}{|c|c|c|c|c|c|c|c|c|c|}
\hline \multirow{2}{*}{$\begin{array}{c}\text { \% of } \\
\text { Ethanol } \\
(\mathbf{v} / \mathbf{v})\end{array}$} & \multicolumn{3}{|c|}{$\mathbf{2 9 8 . 1 5 ~ K}$} & \multicolumn{3}{c|}{ 303.15 K } & \multicolumn{3}{c|}{$\mathbf{3 0 8 . 1 5} \mathbf{K}$} \\
\cline { 2 - 11 } & Slope & $\mathbf{r}^{\mathbf{2}}$ & $\boldsymbol{\varepsilon}_{\text {solvent }}$ & Slope & $\mathbf{r}^{\mathbf{2}}$ & $\boldsymbol{\varepsilon}_{\text {solvent }}$ & Slope & $\mathbf{r}^{\mathbf{2}}$ & $\boldsymbol{\varepsilon}_{\text {solvent }}$ \\
\hline 10 & 125 & 0.999 & 74.49 & 145 & 0.998 & 72.00 & 166 & 0.998 & 71.00 \\
\hline 20 & 98.4 & 0.999 & 69.58 & 114 & 0.999 & 67.32 & 133 & 0.998 & 66.37 \\
\hline 30 & 77.6 & 0.999 & 64.31 & 91.4 & 0.999 & 62.07 & 104 & 0.999 & 61.33 \\
\hline 40 & 63.5 & 0.999 & 58.56 & 75.3 & 0.999 & 56.89 & 87.7 & 0.999 & 56.29 \\
\hline 50 & 52.5 & 0.999 & 52.81 & 63.2 & 0.998 & 51.48 & 73.6 & 0.999 & 50.70 \\
\hline 60 & 44.5 & 0.999 & 46.82 & 53 & 0.999 & 45.77 & 58.5 & 0.999 & 44.98 \\
\hline 70 & 37.1 & 0.999 & 41.07 & 41.4 & 0.997 & 40.08 & 48.8 & 0.998 & 39.26 \\
\hline 80 & 28.9 & 0.999 & 35.21 & 33.7 & 0.998 & 34.61 & 36.8 & 0.996 & 33.89 \\
\hline 90 & 21 & 0.997 & 30.29 & 23.4 & 0.999 & 29.46 & 25.1 & 0.998 & 28.74 \\
\hline 100 & 9.75 & 0.998 & 24.30 & 10.2 & 0.993 & 23.54 & 11.4 & 0.997 & 22.63 \\
\hline
\end{tabular}

It is a known fact that the ionic conductance increases with temperature and decreases with concentration. The highest or the limit equivalent conductance can only be achieved with the extrapolation of conductance to the zero concentration. This is the result which can be obtained with all ions. Here, we calculated the Limiting molar conductance in Table 5 from our investigated system with the help of Table 1-3.

Table 5: Limiting molar conductance $\left(\mathrm{mS} \mathrm{cm} \mathrm{mol}^{-1}\right)$ of $\mathrm{NiCl}_{2}$ in ethanol-water system at different temperatures

\begin{tabular}{|c|c|c|c|}
\hline \multirow{2}{*}{$\begin{array}{c}\text { \% of } \\
\text { Ethanol } \\
(\mathbf{v} / \mathbf{v})\end{array}$} & $\mathbf{2 9 8 . 1 5 ~ K}$ & $\mathbf{3 0 3 . 1 5} \mathbf{K}$ & $\mathbf{3 0 8 . 1 5} \mathbf{~}$ \\
\cline { 2 - 4 } & $\begin{array}{c}\text { Limiting molar } \\
\text { conductance }\end{array}$ & $\begin{array}{c}\text { Limiting molar } \\
\text { conductance }\end{array}$ & $\begin{array}{c}\text { Limiting molar } \\
\text { conductance }\end{array}$ \\
\hline 10 & 245 & 262 & 277 \\
\hline 20 & 176 & 207 & 215 \\
\hline 30 & 144 & 170 & 185 \\
\hline 40 & 124 & 132 & 154 \\
\hline 50 & 98.6 & 117 & 132 \\
\hline 60 & 83.4 & 100 & 116 \\
\hline 70 & 73.8 & 88.1 & 95.9 \\
\hline 80 & 62.3 & 76.8 & 84.6 \\
\hline 90 & 51.7 & 55.2 & 56.5 \\
\hline 100 & 29.5 & 31.3 & 33.8 \\
\hline
\end{tabular}


The experimental specific conductivities of Nickel Chloride as a function of the salt concentration at $298.15 \mathrm{~K}, 303.15 \mathrm{~K}$ and $308.15 \mathrm{~K}$ of ten different ethanol-water binary mixtures containing 10,20 , $30,4050,60,70,80,90$ and $100 \%(\mathrm{v} / \mathrm{v})$ ethanol are depicted in figs. 2-4. These figures show that the specific conductivities linearly increase with increasing concentration within the concentration range investigated here. The increase in the conductance with concentration is due to an increase in the ionic density in the solution.

The conductivity is also the function of temperature, so it is well known fact that specific conductance of an electrolyte increases with increase in temperature. In this study, also the specific conductance of $\mathrm{NiCl}_{2}$ increases with increasing temperatures in ethanol - water mixed solvent media which was also reported in the same solvent system for electrolyte $\mathrm{KNO}_{3}[10]$ and also in methanol-water system for electrolytes $\mathrm{NaBr}$ and $\mathrm{NaI}$ [18]. The increase in specific conductance with temperature is mainly due to the increase in thermal energy of the ions which responsible for the mobility of ions, decrease in the viscosity of the solvent, and also an increase in the degree of ionization.

There is the linear relationship between specific conductance and the electrolyte concentrations for all concentrations and solvent composition investigated. But, it has been studied earlier that the conductivity value decreases with increase of ethanol in the system $[10,19]$. The specific conductance of the electrolyte nickel chloride also shows the same pattern as reported earlier in the literature, i.e. decreases with increase of ethanol content for the studied ethanol-water mixed solvent system (shown in figs. 2, 3 and 4). The presence of ethanol reduces the dielectric constant of the binary solvent phase (shown in Table 4 and fig.1) by breaking the structure of water, disturbed the original orientations of water molecules. The decrease in dielectric constant of binary solvent makes easier for the formation of ion-pairs in the solution phase. The decrease in specific conductance can also be explained in terms of having the small ionizing effect of the solvent on electrolytes, so the electrostatic forces between oppositely charged ions would be appreciable and will have the small value of the specific conductance.

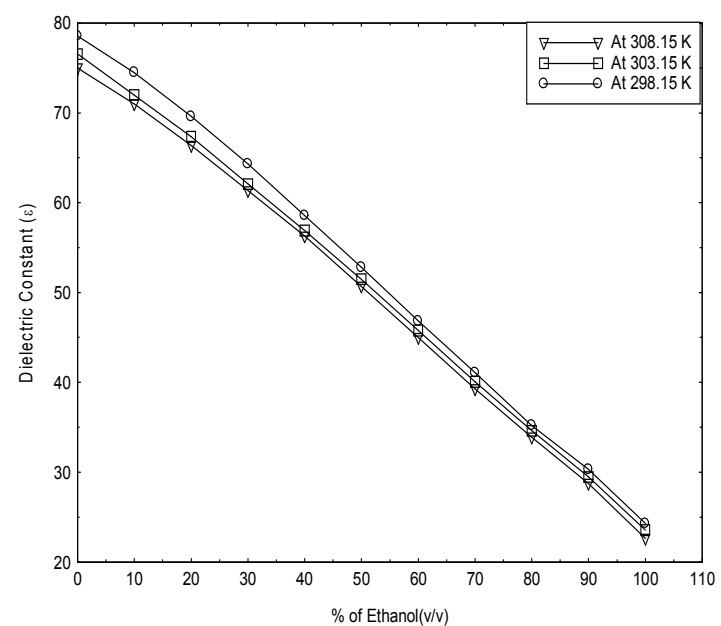

Figure 1: Dielectric constant as a function of the volume fractions of Ethanol at different temperatures.

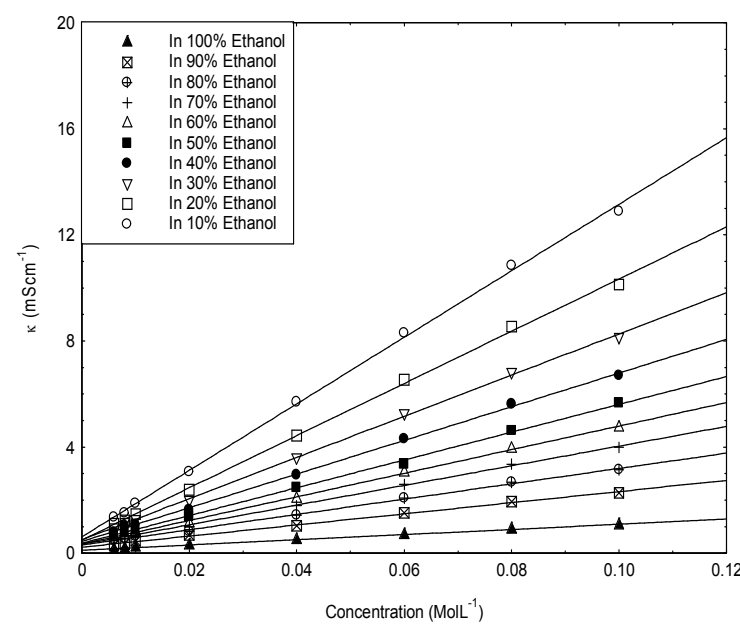

Figure 2: Sp. conductance of $\mathrm{NiCl}_{2}$ as a function of concentration at $298.15 \mathrm{~K}$ (Solid lines - fitted graphs). 


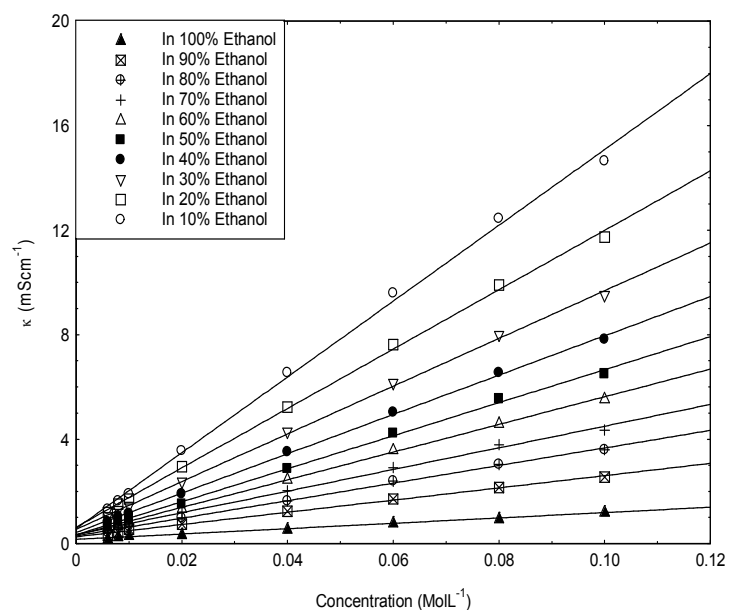

Figure 3: Sp. conductance of $\mathrm{NiCl}_{2}$ as a function of concentration at $303.15 \mathrm{~K}$ (Solid lines - fitted graphs).

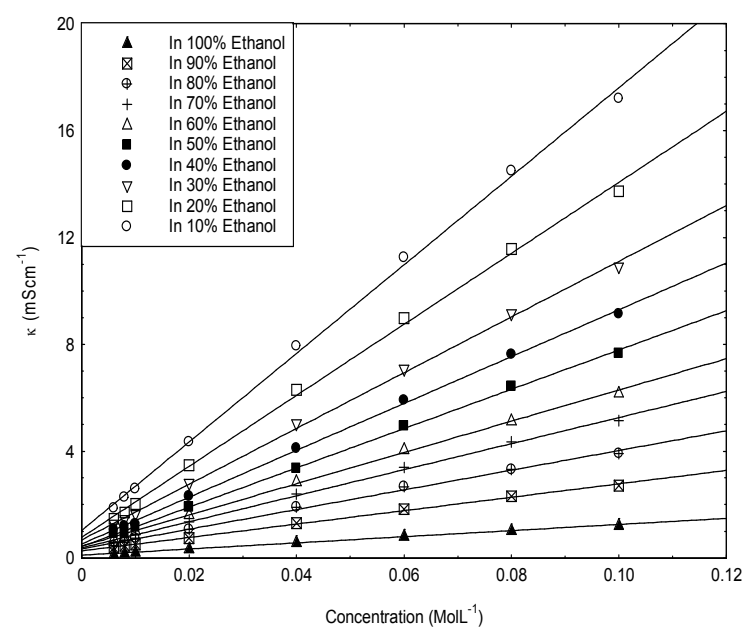

Figure 4: Sp. conductance of $\mathrm{NiCl}_{2}$ as a function of concentration at $308.15 \mathrm{~K}$ (Solid lines - fitted graphs).

\section{Conclusion}

The conductometric data have been obtained to study the variation of specific conductance of nickel chloride with the concentration, temperature, and solvent composition in ethanol- water mixed solvent media. On the basis of results and discussion of the experimental study, it is found that the specific conductance increases with increasing concentration and temperature of the electrolytic solutions over the entire concentration range investigated whereas the specific conductance of the same electrolyte in same binary mixed solvent media decreases with decreasing dielectric constant of solvent composition.

\section{Acknowledgments}

The authors are grateful to Professor Dr. Sujeet Kumar Chatterjee, Department of Chemistry, Mahendra M. A. M. Campus, Tribhuvan University, Biratnagar, Nepal for the valuable suggestions and discussions. The authors are also thankful for Research Management Cell, Damak Multiple Campus for financial support. The authors also thankful to Associate Professor Sant Kumar Bhagat, Campus Chief and Madan Bahadur Thapa, Head of the department of Chemistry, Damak Multiple Campus, Tribhuvan University, Damak, Nepal for providing research facilities to conduct this research work. 


\section{References}

[1] A. Andrek, M. M. Lencka, Ind. Eng. Chem. Res., 36 (1997) 1932. http://dx.doi.org/10.1021/ie9605903

[2] G. T. Janz, R. P. T. Tomkins, Non Aqueous Electrolytes Handbook, Academic Press: London.( 1972) Vol.1.

[3] J. J. Lee, M. D. Lee, Korean J. Chem. Eng., 5 ( 1988) 5.

[4] M. D. Lee, J. J. Lee, Seoul Univ. Faculty papers, 4 (c) (1975) 21.

[5] J. S. Chazhoor, T. P. Radhakrishnan, J. Phys. Chem., 60 (1979) 151.

[6] A. Bhattarai, S. K. Sah, Res. J. Chem. Sci., 1 (2011) 1.

[7] A. Bhattarai, J. Raut, J. Alpine Chemistry, 2 (2011) 44.

[8] A. Bhattarai, S. Neupane, Kath. Univ. J. Sci. Eng. \& Tech., 8 (2012)1.

[9] P. Baskovic, V. Sakol, R. Tomas, A. Prkic, Int. J. Electrochem. Sci. 8 (2013) 10961.

[10] N. Basnet, R. B.Thapa, R. Dhakal, D. Pokhrel, S. K. Shah, A. Bhattarai, Modern Trends in Science and Technology (2013) 136.

[11]Jr J.E. Lind, J.J. Zwolenik, R.M. Fuoss, J.Am.Chem.Soc., 81(1959) 1557.

[12]B. Das, D.K. Hazra, Bull. Chem. Soc. Jp., 65 ( 1992) 3470.

http://dx.doi.org/10.1246/bcsj.65.3470

[13]B. Das, D.K. Hazra, J. Phys. Chem., 99 ( 1995) 269.

http://dx.doi.org/10.1021/j100001a042

[14]F. Frank, D.J.G. Ives, Quartely Review, 20 (1966) 1.

[15]T. Pradhan, P. Ghosal, R. Biswas, J. Chem. Sci., 120 (2008) 275.

http://dx.doi.org/10.1007/s12039-008-0033-0

[16]S. K. Thakur, S. Chauhan, J. Chem. Pharma. Res, 3 (2011) 657.

[17]V. K. Syal, S.K. Thakur, S. Chauhan, P.Sharma, Int. J. Thermophys. 26(2005) 807. http://dx.doi.org/10.1007/s10765-005-5579-1

[18] S. Zhang, H. Li, S. Dai, T. Wang, S. Han, J. Chem. Eng. Data, 42 (1997) 651. http://dx.doi.org/10.1021/je960235j

[19] S. Zhang, S. Han, Y. Jin, Acta Physico- Chemica Sinica, 12 ( 1996) 75. 